\title{
Major depressive disorder prevalence and risk factors among Syrian asylum seekers in Greece
}

Danielle N. Poole ${ }^{1,2^{*}}$, Bethany Hedt-Gauthier ${ }^{3,4}$, Shirley Liao ${ }^{3}$, Nathaniel A. Raymond ${ }^{2}$ and Till Bärnighausen ${ }^{1,5,6}$

\begin{abstract}
Background: Over one million Syrian asylum seekers have travelled to Greece with the ultimate aim of reaching other countries in western Europe. Depression prevalence and associated sociodemographic and displacement characteristics have been reported for resettled migrants. However, the prevalence of major depressive disorder (MDD) and its risk factors have not been described among migrants engaged in the asylum process ensuing from the Syrian crisis. This study provides new data about the mental health status of migrants in transition in the context of protracted asylum procedures.
\end{abstract}

Methods: We conducted a cross-sectional survey in a Syrian refugee camp in the Attica region of Greece from January 16-31, 2017. Individuals $\geq 18$ years of age with verbal Arabic or English language skills were eligible to participate. The Patient Health Questionnaire-8 (PHQ-8), an eight-item validated diagnostic and severity measure, was used to screen for MDD. We analysed the relationships between MDD and sociodemographic and displacement characteristics using multivariable logistic regression.

Results: A total of 135 surveys were completed, representing 40\% of the adult population in the refugee camp. The mean age of the participants was 30 years (18-61 years); women comprised $41 \%$ of the sample; $74 \%$ of the participants had ever married; $67 \%$ had children; and $33 \%$ of participants had not attended secondary school, including $11 \%$ who had never attended school. Median time since departing the country of origin was 12 months ( $<1-74$ months). Median time spent in the asylum process in Greece was 10 months (<1-49 months). MDD was detected in 44\% (95\% Cl: 37-50) of participants. Being a woman (Adjusted Odds Ratio [AOR]: 3.23, $p=0.019$ ), each additional child (AOR: 1.61, $p=0.006$ ), and increased time in the asylum process in Greece (AOR: 1.15, $p=0.043$ ) were significant risk factors for MDD. Ever being married was associated with reduced odds of MDD (AOR: 0.23, $p=0.042$ ).

Conclusions: Syrian migrants face an extraordinarily high burden of MDD as they seek asylum. Incorporation of screening and treatment into service provision within refugee camps is urgently needed, particularly as migrants spend extended periods of time in transition due to protracted asylum procedures.

Keywords: Migrants, Refugees, Global mental health, Conflict, Depression

\footnotetext{
* Correspondence: dani@mail.harvard.edu

'Department of Global Health and Population, Harvard T.H. Chan School of

Public Health, 665 Huntington Avenue, Boston, MA 02115, USA

${ }^{2}$ Signal Program, Harvard Humanitarian Initiative, Harvard T.H. Chan School of

Public Health, 14 Story Street, Cambridge, MA 02138, USA

Full list of author information is available at the end of the article
}

C The Author(s). 2018 Open Access This article is distributed under the terms of the Creative Commons Attribution 4.0 International License (http://creativecommons.org/licenses/by/4.0/), which permits unrestricted use, distribution, and reproduction in any medium, provided you give appropriate credit to the original author(s) and the source, provide a link to the Creative Commons license, and indicate if changes were made. The Creative Commons Public Domain Dedication waiver (http://creativecommons.org/publicdomain/zero/1.0/) applies to the data made available in this article, unless otherwise stated. 


\section{Background}

An estimated 4.5 million Syrians have sought asylum in neighboring countries since the start of the Syrian conflict in 2011 [1], including one million who have travelled to Greece with the ultimate aim of reaching other peaceful countries in western Europe [2]. Evidence suggests that the "healthy migrant effect" - the often-observed phenomenon that migrants are on average healthier than their host populations - does not apply to forced migrants fleeing conflict [3]. Instead, forced migrants may face higher rates of health problems, including mental health disorders [4].

Two previous studies found significantly higher rates of post-traumatic stress disorder (PTSD) among Syrian migrants compared to host populations $[5,6]$. However, the emphasis on pre-migration trauma may overshadow other psychological needs of asylum seekers and the roles of displacement-related stressors [7, 8], which have been shown to be important determinants of mental health among Syrian refugees in Turkey [9]. Displacement-related stressors are known to contribute to the development of chronic mental health disorders, including anxiety [10] and major depressive disorders [11-13]. The EU-Turkey Statement of 2016, which assigned the responsibility of processing asylum claims to the first EU member state an asylum seeker entered, has likely contributed to extended asylum procedures for Syrian migrants in Greece and may subsequently have exacerbated the burden of mental health disorders [10]. Furthermore, several studies in post-conflict populations in the Middle East and Nepal have found that current living contexts strongly affect mental health [14]. A narrow focus on past trauma may result in failure to consider the effect of current life circumstances on mental health [15].

The development of depression during the asylum process is likely to undermine individual and societal functioning, which are essential for the survival and eventual resettlement of forced migrants [16]. Depression is also likely to lead to adverse acculturation outcomes [17].

While the early screening and treatment of depression may be expected to confer benefits, measures to detect or prevent psychological morbidity during the asylum-seeking phase of migration are only inconsistently implemented [18]. Previous studies reported estimates of the prevalence of depression among Syrians pre-conflict [19] and upon resettlement [20]. However, to date no study has measured the prevalence of depression among Syrians undergoing the protracted asylum process in refugee camps [21]. Furthermore, although sociodemographic characteristics (i.e. age, sex) and displacement-related stressors associated with depression and their moderating effects have been reported for resettled migrants [11], risk factors contributing to depression among Syrian asylum seekers have not been described.
In this study, we examined the prevalence and risk factors of major depressive disorder (MDD) among Syrians undergoing the asylum process in a European refugee camp. The purposes of the study are to 1) determine the prevalence of MDD among Syrian migrants living in a refugee camp in Greece using a validated measure, and 2) identify sociodemographic and displacement characteristics that could be risk factors for MDD. Quantifying the need for mental health services by estimating the prevalence of MDD and associated risk factors is the first step toward developing intervention programming for this population.

\section{Methods}

This study included a face-to-face cross-sectional survey in a camp designated for Syrian refugees located in the Attica region of Greece. Data were collected from January 16-31, 2017. Access to the camp was granted by the International Organization for Migration (IOM), which managed camp operations.

\section{Sample size and sampling strategy}

The sampling frame included all adults residing in the refugee camp during the study period (estimated 336 individuals). Individuals $\geq 18$ years of age with verbal Arabic or English language skills were eligible to participate. A minimum representative sample of 97 participants was needed to estimate the prevalence of MDD with $\pm 10 \%$ precision in the $95 \%$ confidence intervals ( $95 \% \mathrm{CIs})$.

This study used mixed sampling procedures, utilizing a map of the camp to facilitate sampling. As shown in Fig. 1, camp inhabitants reside in containers, the primary housing unit. The containers provide housing for up to eight individuals, and are organized into blocks. In the first phase of sampling, due to the highly vulnerable nature of the population, camp management announced that a research study was being undertaken in the camp on the topic of migrant health. All eligible adults who volunteered to take part in the study were included $(n=90)$. No personally identifiable information was collected in order to protect the participants' identities. The container numbers from which participants had been recruited were recorded to facilitate sampling in the second wave of recruitment. However, the container numbers were not linked to the survey data, precluding the identification of participants by container number.

After establishing familiarity with and receiving positive feedback regarding the research from camp management and the study population, a second container-based phase of sampling was deemed feasible and was performed to increase the representativeness of the sample. Briefly, a systematic sample was drawn using the camp map to recruit all eligible adults from exactly half the containers in each block. First, blocks in which less than half of the containers were represented during the first phase of 


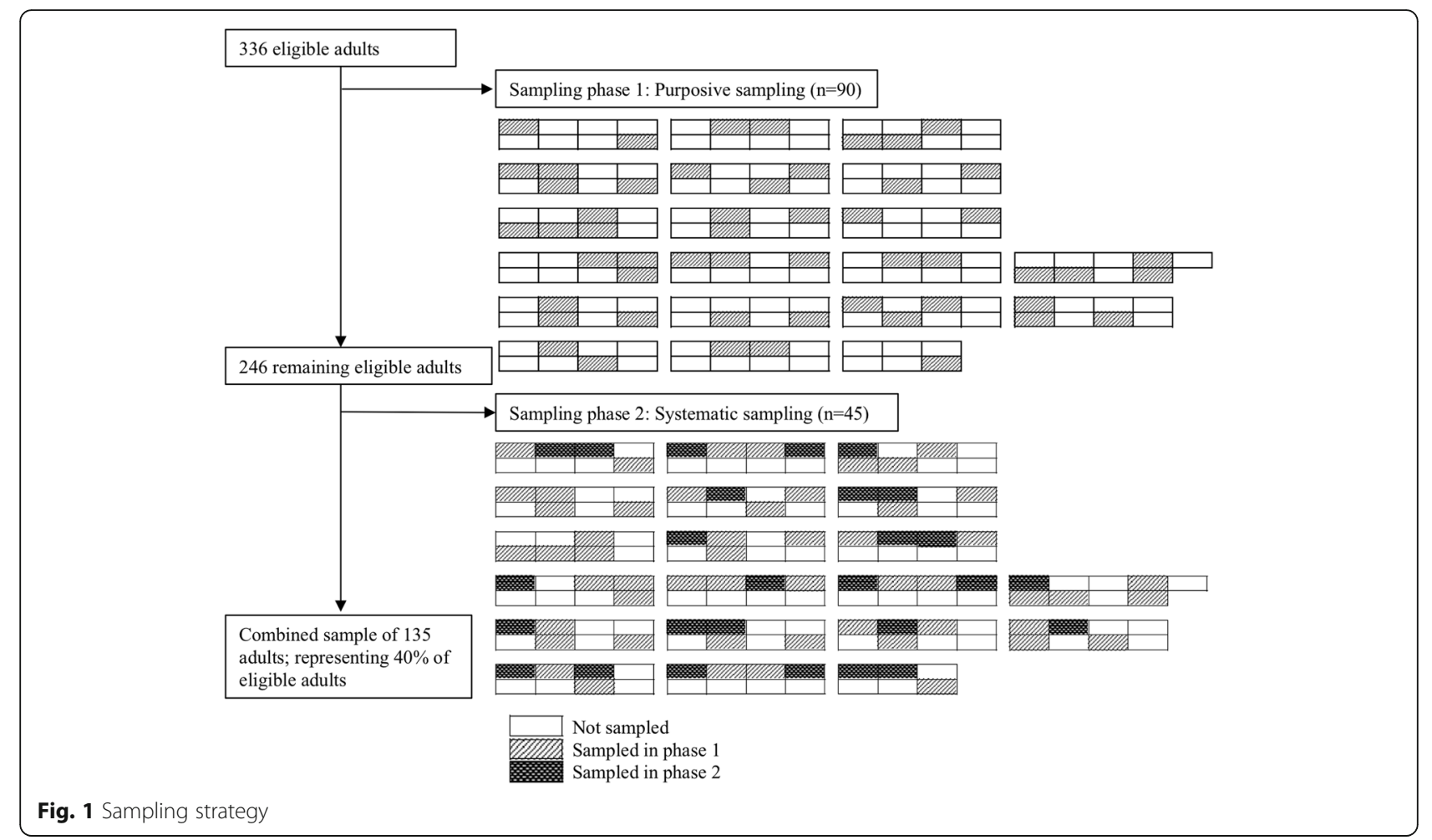

sampling were identified and included in the second phase of sampling. All adults residing in the most north-western container of each block were recruited to participate in the study. Next, adults residing in neighbouring containers that were not previously sampled in the first phase were recruited, starting with the most western container and moving east. This process was repeated until all eligible adults from exactly half the containers in each block were recruited to participate in the study, producing an even distribution of sampled containers across the camp. Forty-five participants were included in the second phase of sampling, with a response rate of $92 \%$. An illustration of the mixed sampling strategy is presented in Fig. 1. The total combined sample from the first and second phases of sampling was 135 participants.

\section{Procedures}

All survey items were translated to and back-translated from Arabic. Face-to-face interviews took place in an area with audio privacy. There were several settings used to achieve this purpose, including a private area inside the participant's container or outside on the veranda or in another outdoor area with audio privacy. The survey was administered by a member of the research team paired with Arabic-English interpreters. All members of the research team completed research training via the Collaborative Institutional Training Initiative and had experience working with migrant populations. The interpreters had professional experience working with Syrian refugee populations.

\section{Major depressive disorder}

The primary outcome was the prevalence of MDD. MDD screening was conducted with the Patient Health Questionnaire-8 (PHQ-8) [22]. There is a lack of screening tools for depression severity specifically validated among Syrian refugees. However, the PHQ-8 has been used to assess MDD among migrant populations [23, 24], and has been validated in Arabic [25, 26]. A cut-off score of 10 or more was used for MDD on the basis of validation studies [22, 27]. The detection of MDD by the persistence and severity of depressive symptoms for two weeks [28] is an important threshold for clinical diagnostic assessments and treatment [29]. In our study, the PHQ-8 had a Cronbach's $\alpha$ of 0.77 , indicating satisfactory reliability of this scale among the study population.

Participants that reported depressive symptoms in the last two weeks were referred for assessment by an on-site psychologist employed by the IOM.

\section{Participant characteristics}

Sociodemographic and displacement characteristics were collected using a survey. Level of education was used as a proxy measure of socioeconomic status in country of origin. The interview date, date of departure from country of origin, and date of arrival in Greece were 
used to calculate the total time displaced and time seeking asylum in Greece.

\section{Statistical analysis}

The point prevalence of MDD was reported with Wald 95\% CIs. Finite population correction was applied to adjust the prevalence estimate such that the variance applies only to the unsampled proportion of the population [30]. Missing data for items used to measure MDD status were replaced with minimum values, indicating the absence of depression, to produce the most conservative prevalence estimate. Sensitivity analyses were performed by imputing the maximum responses for observations with missing data for items used to assess depression status.

We addressed potential selection bias introduced by the mixed sampling methods in two ways. First, we assessed the balance of the sociodemographic characteristics (age and sex) of participants sampled in the first sampling phase with those sampled in the second phase. We used Welch's approximation t-test to compare the age distribution of the study subsamples, accounting for heterogeneous variance due to differences in the sample sizes. Next, we used Pearson's chi-square test to assess differences in the sex distributions of the study subsamples. We compared the prevalence of MDD between the sampling phases with Pearson's chi-square test to evaluate selection bias on the outcome between the purposive and systematic samples.

Second, to determine whether the final combined sample (hereafter, the study sample) could be considered pragmatically random and representative of the sampling frame, we used camp census data collected during the study period to evaluate differences between the study sample and the camp population. Welch's approximation t-test and Pearson's chi-square test were used to compare the age and sex distributions of the study sample and the camp population, respectively. We additionally calculated the age- and sex- standardized MDD prevalence estimate using the population census data. After determining that the combined sample could be considered representative of the study population (Table 1), the total combined sample of 135 participants, representing $40 \%$ of the adult camp population, was used in the main analyses.
We used descriptive statistics to quantify the participants' sociodemographic and displacement characteristics. Associations between sociodemographic and displacement characteristics and MDD status were analysed by logistic regression and are reported as Unadjusted Odd Ratios (UORs) with 95\% CIs.

We used multivariable regression to predict MDD with sociodemographic and displacement characteristics. Our model includes the following sociodemographic characteristics: gender, age, educational attainment, marital status, and number of children. Gender is included to account for established differences in depression prevalence between men and women [31]. Continuous age and age squared are included because depression prevalence has been shown to have a U-shaped distribution across the lifespan [32]. Educational attainment is included to account for the expected protective effect of increased education against depression [33]. Marital status, a known protective predictor of depression [34], is also included in the model. The number of children is included to capture the previously reported risk of depression associated with increased family size, which may exacerbate housing and financial pressures [35]. Total time since forced displacement represents time since exposure to conflict-related trauma, which has been shown to have an inverse relationship with the risk of depression [36]. Finally, time in the asylum process is included on the basis of literature demonstrating the deleterious effect of detainment and temporary protection on migrant mental health [13].

Adjusted Odds Ratios (AOR) with 95\% CIs are reported for associations in the final multivariable logistic regression model. All analyses are complete case analyses. Statistical analyses were performed using Stata version 14.2 [37].

\section{Ethical considerations}

This study was under ethics review, oversight, and governance both in Greece and in the United States by the IOM Greek research ethics advisory board and the Institutional Review Board of the Harvard T. H. Chan School of Public Health (Protocol IRB16-2015), respectively. Informed consent was obtained orally from all participants to avoid the potential risks of collecting participant names.

Table 1 Sample representativeness

\begin{tabular}{|c|c|c|c|c|c|c|c|c|}
\hline \multirow[t]{2}{*}{ Sample description } & & \multicolumn{4}{|c|}{ Age (years) } & \multicolumn{3}{|c|}{ Percent women } \\
\hline & & $\bar{N}$ & Median & IQR & $\overline{p \text {-value }}{ }^{\dagger}$ & $\bar{N}$ & $\%$ & $p$-value f $^{\prime}$ \\
\hline \multirow[t]{2}{*}{ First and second sampling phases } & Second phase & 45 & 31 & $24-38$ & & 26 & 57.8 & \\
\hline & First phase & 90 & 30 & $25-36$ & 0.93 & 29 & 32.2 & 0.004 \\
\hline \multirow[t]{2}{*}{ Combined sample and the camp population } & Camp population & 346 & 30 & $24-40$ & & 154 & 45.9 & \\
\hline & Combined sample & 135 & 30 & $24-37$ & 0.11 & 55 & 40.7 & 0.31 \\
\hline
\end{tabular}

${ }^{\dagger}$ Welch's approximation t-test

${ }^{\ddagger}$ Pearson's chi-square test 


\section{Results}

A total of 135 interviews were completed. As shown in Table 1, the age and sex distributions of the combined study sample did not significantly vary from those of the camp population at the time of the study (median age: 30 years for both, $p<0.11$; and the percent women: 41 and $46 \%$, respectively, $p<0.31$ ). Therefore, for simplicity, we used the combined study sample in all analyses.

Participant sociodemographic and displacement characteristics are presented in Table 2. All (100\%) participants had recently fled the Syrian conflict and the majority (89\%) were of Syrian nationality. We did not record the nationality of those migrants who were not Syrian to maintain the anonymity of the collected data. The mean age of the participants was 30 years (range: $18-61$ years); women comprised $41 \%$ of the sample; $74 \%$ of the participants had ever married; and $67 \%$ had children. $33 \%$ of participants had not attended secondary school, including $11 \%$ who had never attended any school. The median time since departing the country of origin was 12 months $(<1-$ 74 months). The median time spent in the asylum process in Greece was 10 months (<1-49 months).

MDD was detected in 44\% (95\% CI: 37-50) of participants. The prevalence of MDD did not significantly vary between the first and second sampling phases (43\% vs. $44 \%$, respectively, $p=0.902$ ). The age- and sex-standardized MDD prevalence estimate was $46 \%$.

Unadjusted and adjusted associations between sociodemographic and displacement characteristics and MDD status are presented in Table 3 . Women had a significantly increased risk of MDD compared to men (UOR: 2.73, $p=$ 0.005). Each additional child conferred significantly increased odds of MDD (UOR: 1.19, $p=0.040$ ). MDD prevalence did not differ significantly by age, age squared, or educational attainment. Increased total time displaced (months) (UOR: 1.01, $p=0.179$ ) and in the asylum process in Greece (months) (UOR: 1.10, $p=0.054$ ) also exhibited trends toward increased odds of MDD.

In the multivariable analyses, sociodemographic characteristics significantly associated with increased odds of MDD included being a woman (AOR: 3.23, $p=0.019$ ) and each additional child (AOR: $1.61, p=0.006$ ). Marriage had a protective effect against MDD (AOR: 0.23, $p=0.043$ ). Controlling for other factors, the odds of MDD increased $15 \%$ for each additional month spent in the asylum process in Greece (AOR: 1.15, $p=0.044$ ). The average probabilities of MDD by months in Greece, while retaining the observed values for all other variables, are presented as percentages in Fig. 2. The inclusion of a dummy variable for sample phase in the adjusted model was not significant and did not qualitatively change the parameter estimates.

\section{Discussion}

The prevalence of MDD was extremely high among Syrian asylum seekers in a refugee camp in Greece. This prevalence was nearly ten times higher than the depression prevalence among Syrians pre-conflict [19] and the global prevalence of depression [38]. The prevalence observed in this study was also nine times higher than the prevalence previously reported in a meta-analysis of studies among

Table 2 Participant sociodemographic and displacement characteristics

\begin{tabular}{lll}
\hline Participant characteristics & Total $(n=135)$ & Major depressive disorder $(n=59)$ \\
\hline Nationality $n(\%)$ & $120(88.9 \%)$ & $53(89.8 \%)$ \\
Syrian & $15(11.1 \%)$ & $6(10.2 \%)$ \\
Other & & $27(45.8 \%)$ \\
Gender $n$ (\%) & $80(59.3 \%)$ & $32(54.2 \%)$ \\
Men & $55(40.7 \%)$ & $30(22-39)$ \\
Women & $30(24-37)$ & $8(13.8 \%)$ \\
Age median (years, IQR) & & $13(22.4 \%)$ \\
Education $n$ (\%) & $15(11.4 \%)$ & $22(37.9 \%)$ \\
$\quad$ None & $29(22.0 \%)$ & $15(25.9 \%)$ \\
Any primary & $38(28.8 \%)$ & $15(25.9 \%)$ \\
Any secondary & $50(37.9 \%)$ & $43(74.1 \%)$ \\
Any tertiary or higher & & $2(0-4)$ \\
Marital status $n$ (\%) & $34(25.6 \%)$ & $12.0(10.7-45.7)$ \\
Single, never married & $99(74.4 \%)$ & $10.4(10.1-10.9)$ \\
Ever married & $2(0-4)$ & $12.1(10.7-35.8)$ \\
Number of children median (IQR) & $10.4(9.6-10.8)$ & \\
Total time displaced (months) median (IQR) & & \\
Time in Greece (months) median (IQR) & & \\
\hline
\end{tabular}


Table 3 Associations between participant sociodemographic and displacement characteristics and major depressive disorder

\begin{tabular}{|c|c|c|c|c|}
\hline Participant characteristics & UOR (95\% Cl) & $p$-value & AOR $(95 \% \mathrm{Cl}) n=120$ & $p$-value \\
\hline \multicolumn{5}{|l|}{ Nationality } \\
\hline Syrian & Ref & & Ref & \\
\hline Other & $0.84(0.28-2.52)$ & 0.759 & $1.19(0.31-4.55)$ & 0.798 \\
\hline \multicolumn{5}{|l|}{ Gender } \\
\hline Men & Ref & & Ref & \\
\hline Women & $2.73(1.34-5.55)$ & 0.005 & $3.23(1.21-8.62)$ & 0.019 \\
\hline Age & $1.00(0.96-1.04)$ & 0.898 & $0.82(0.60-1.13)$ & 0.224 \\
\hline Age squared & $1.00(1.00-1.00)$ & 0.997 & $1.00(1.00-1.00)$ & 0.257 \\
\hline \multicolumn{5}{|l|}{ Education } \\
\hline None & Ref & & Ref & \\
\hline Any primary & $0.71(0.20-2.48)$ & 0.593 & $1.23(0.24-6.43)$ & 0.802 \\
\hline Any secondary & $1.20(0.36-4.00)$ & 0.763 & $3.01(0.59-15.45)$ & 0.186 \\
\hline Any tertiary or higher & $0.38(0.12-1.22)$ & 0.104 & $1.14(0.21-6.17)$ & 0.876 \\
\hline \multicolumn{5}{|l|}{ Marital status } \\
\hline Single, never married & Ref & & Ref & \\
\hline Ever married & $1.00(0.44-2.13)$ & 0.945 & $0.23(0.05-0.95)$ & 0.042 \\
\hline Number of children & $1.19(1.01-1.40)$ & 0.040 & $1.61(1.15-2.25)$ & 0.006 \\
\hline Total time displaced (months) & $1.01(0.99-1.03)$ & 0.179 & $1.01(0.99-1.04)$ & 0.355 \\
\hline Time in Greece (months) & $1.10(1.00-1.22)$ & 0.054 & $1.15(1.00-1.31)$ & 0.043 \\
\hline
\end{tabular}

resettled refugees [4], and one and a half times higher than the prevalence reported among Syrian migrants in non-refugee camp settings in Jordan [20].

The high prevalence of MDD among Syrian asylum seekers supports the hypothesis that the "healthy migrant effect" may only apply to depression status when migration is motivated by economic reasons [39, 40].
Additionally, the very high prevalence of MDD among Syrian asylum seekers may be explained by the particular plight of fleeing conflict, the social and physical conditions in the refugee camp, as well as the protracted asylum process reported by the participants, a period extending beyond one year on average in Greece since the adoption of the EU-Turkey Statement [21]. Our finding that the

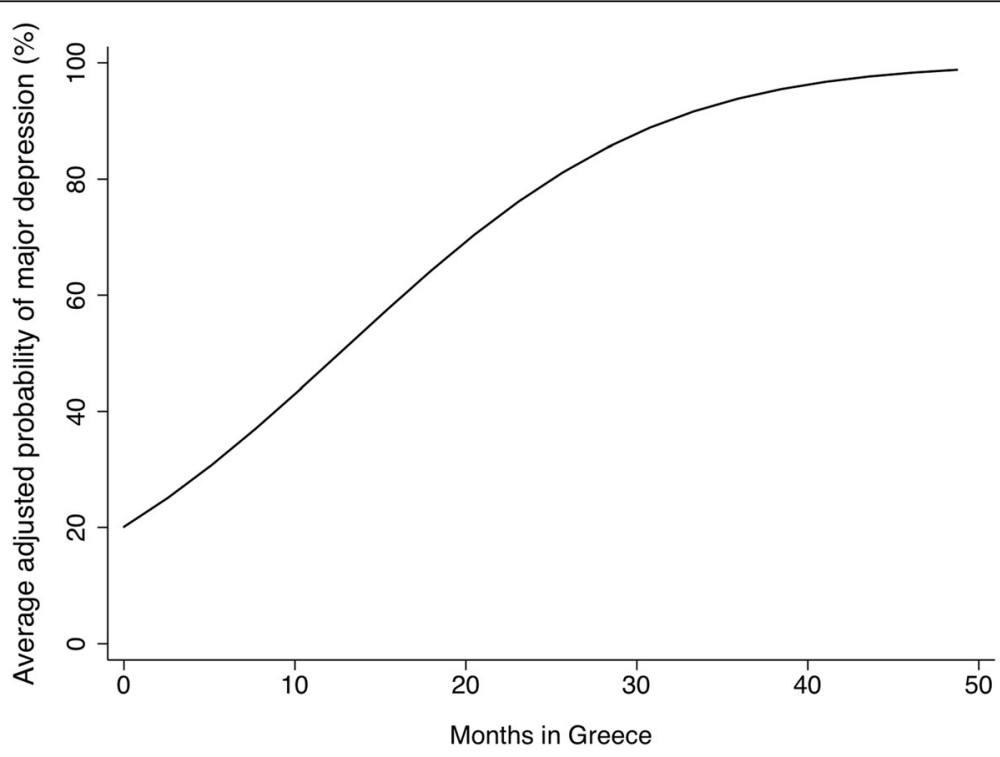

Fig. 2 Major depressive disorder gradient with time seeking asylum. Average adjusted predictions at representative values of months in Greece 
prevalence of MDD increases with time in Greece supports the hypothesis that the protracted asylum process contributes to the development of depression among Syrian migrants. This finding is plausible, because migrants in refugee camps may lose hope for a better life as the transition phase waiting for asylum extends. In our study, the median time in the refugee camp was ten months. Previous studies have found reductions in depression with increased time since exposure to conflict [36]. Furthermore, while the study participants had been exposed to the Syrian conflict, assessing trauma as a risk factor for major depression was outside the scope of the present study. Our results are thus an important addition to the evidence base suggesting a countervailing time trend in depression prevalence if migrants are not quickly moved to resettlement and stable new life situations but instead remain in the uncertain situation of the asylum-seeking process in refugee camps.

MDD status varied significantly by several key sociodemographic characteristics. Women experienced a significantly higher burden of depression relative to men. Globally, the burden of depression is $50 \%$ higher among women [41], similar to the magnitude of the relationship between sex and MDD status observed in this study. The mental health literature includes extensive research about the physiological and psychosocial mechanisms that may explain the preponderance of depression among women [42]. Importantly, the effect of gender was independent of other sociodemographic and displacement characteristics in our study. A previous study among Syrian refugees in Jordan attributed the reported absence of a gender disparity in depression status as an artifact of equal exposure to trauma between men and women [20]; however, our results suggest the persistence of a gender disparity in the prevalence of depression.

Marriage conferred a protective effect against depression, consistent with the literature both globally and among Syrian refugees. The mechanism through which increased education reduces the odds of major depression may be the ability to access social support and resources, which may be dependent on marital status.

Our study contributes to the existing evidence on migrant mental health by showing evidence of significantly increased odds of major depression with each additional child. This finding provides further motivation for the urgency of screening and treatment of depression among asylum seekers, as parental depression and PTSD are significantly associated with negative and withdrawn parenting and adverse child physical and psychosocial health $[43,44]$, while the remission of parental depression predicts improved functioning in their children [45].

Our findings have several important policy implications. First, the overall high prevalence of MDD in this refugee camp motivates the need for consistent screening and treatment. Second, the magnitude of the gender disparity in the global prevalence of depression was also observed among our study population of Syrian migrants. Epidemiological research of depression among migrants, and subsequent intervention design and implementation, should be responsive to the particular situations faced by women in refugee camps. Third, familial characteristics such as marital status and number of children may be important protective and risk factors, respectively, for the development of depression.

Time spent in the refugee camp is a significant, and modifiable, risk factor for MDD. In light of the high prevalence of MDD, even upon arrival in camp, screening and treatment are necessary both at arrival and throughout the duration of time spent in camp in order to identify baseline and incident depression. Implementation research can contribute to reducing the burden of depression among asylum seekers by identifying best practices in relation to screening and treatment strategies. Such interventions must be responsive to the socioeconomic factors associated with depression, particularly so as not to exacerbate gender disparities or the risk posed by larger families. Ultimately, reducing the duration of time spent in the asylum process, both in camps and in reception centers, and thus the adverse effect of detainment and temporary protection on depression, should be prioritized.

Our study has several limitations. First, selection on depression status itself as well as on other participant characteristics may have biased the prevalence estimate. Biases resulting from selection on the outcome, depression, can theoretically be addressed using Heckman-type selection models. For this purpose, we have developed variants of Heckman-type selection models in other survey applications, using the identity of the interviewer as a selection variable [46-49]. In this study, however, we did not employ a sufficiently large number of interviewers to be able to exploit variation in interviewer identity for Heckman-type selection models. In future larger survey studies on depression among migrants, we will have the opportunity to apply Heckman-type selection models to correct for potential selection on depression. Additionally, selection on other participant characteristics may have biased our results. Comparisons of the final combined sample with camp census data suggest our sample was representative of the camp adult population age and sex distributions, and the age- and sex-standardized prevalence estimate was similar to the sample prevalence estimate, providing further evidence of the representativeness of our sample. Nonetheless, comparability of measured characteristics does not exclude the potential for bias resulting from unmeasured characteristics, e.g., general propensity to engage and extraversion (which are likely lower among people with depression). 
Second, while our findings suggest potential risk and protective factors of major depression among migrants, the cross-sectional nature of our study precludes causal inference. Future prospective designs could increase the strength of causal inferences regarding the effects of sociodemographic and displacement characteristics. Randomized controlled intervention studies could strengthen the evidence-base of the effectiveness of psychological treatments, including problem-solving counselling, interpersonal therapy, cognitive behavioral therapy, and behavioral activation, administered by community health workers or via mHealth platforms [50-53].

Finally, the external generalizability of our findings may be limited by camp-level characteristics specific to our study settings. However, other refugee camps in mainland Greece, under the jurisdiction of Greece's Ministry of Migration, have similar observable characteristics.

\section{Conclusions}

Syrian migrants face an extraordinarily high burden of MDD during the asylum process. Time spent in camps is a significant risk factor for MDD that can be immediately alleviated by expediting resettlement. Incorporation of depression screening and treatment into service provision within refugee camps is urgently needed to mitigate the effects of time in camps as governments work to address the protracted asylum process.

\section{Abbreviations}

AOR: Adjusted odds ratio; IOM: International Organization for Migration; MDD: Major depressive disorder; PHQ-8: Patient Health Questionnaire-8 item; PTSD: Post-traumatic stress disorder; UOR: Unadjusted odds ratio

\begin{abstract}
Acknowledgements
The authors would like to thank the individuals who generously shared their time and experiences for the purposes of this study. The authors also thank Drs. Marcia Castro and Stéphane Verguet for their critical review. Finally, the authors also express gratitude to the International Data Responsibility Group fellowship team: Jos Berens, Dr. Mark Latonero, and Julie Ricard.
\end{abstract}

\section{Funding}

This study was supported by the International Data Responsibility Group. The funding source had no role in study design; in the collection, analysis and interpretation of data; in the writing of the report; or in the decision to submit the paper for publication.

\section{Availability of data and materials}

The datasets generated and analyzed during the current study are not publicly available to protect the privacy of the participants, but are available from the corresponding author on reasonable request.

\section{Authors' contributions}

DP designed the study, collected, analysed and interpreted the data, and wrote the report. NR helped design the study, interpreted the data, and revised the report. BHG, SL, and TB supported data interpretation and revised the report. All authors read and approved the final manuscript.

\section{Ethics approval and consent to participate}

This study was under ethics review, oversight, and governance both in Greece and in the United States by the IOM Greek research ethics advisory board and the Institutional Review Board of the Harvard T. H. Chan School of Public Health (Protocol IRB16-2015), respectively. Oral informed consent was obtained from all participants.
Consent for publication

Not applicable.

\section{Competing interests}

The authors declare that they have no competing interests.

\section{Publisher's Note}

Springer Nature remains neutral with regard to jurisdictional claims in published maps and institutional affiliations.

\section{Author details}

'Department of Global Health and Population, Harvard T.H. Chan School of Public Health, 665 Huntington Avenue, Boston, MA 02115, USA. ${ }^{2}$ Signal Program, Harvard Humanitarian Initiative, Harvard T.H. Chan School of Public Health, 14 Story Street, Cambridge, MA 02138, USA. ${ }^{3}$ Department of Biostatistics, Harvard T.H. Chan School of Public Health, 665 Huntington Avenue, Boston, MA 02115, USA. ${ }^{4}$ Department of Global Health and Social Medicine, Harvard Medical School, 641 Huntington Avenue, Boston, MA 02115, USA. Institute for Public Health, Faculty of Medicine, Heidelberg University, Im Neuenheimer Feld 130.3, 69120 Heidelberg, Germany. ${ }^{6}$ Africa Health Research Institute, Mtubatuba, KwaZulu-Natal 3935, South Africa.

Received: 28 December 2017 Accepted: 10 July 2018

Published online: 24 July 2018

\section{References}

1. UNHCR. Syria regional refugee response - Regional Overview [Internet]. Available from: https://data2.unhcr.org/en/situations/syria.

2. UNHCR. The Mediterranean Refugees/Migrants Data Portal [Internet]. Available from: http://data2.unhcr.org/en/situations/mediterranean.

3. Zimmerman C, Kiss L, Hossain M. Migration and health: a framework for 21st century policy-making. PLoS Med. 2011;8(5):e1001034.

4. Fazel M, Wheeler J, Danesh J. Prevalence of serious mental disorder in 7000 refugees resettled in western countries: a systematic review. Lancet. 2005;365(9467):1309-14.

5. Alpak G, Unal A, Bulbul F, Sagaltici E, Bez Y, Altindag A, et al. Post-traumatic stress disorder among Syrian refugees in Turkey: a cross-sectional study. Int J Psychiatry Clin Pract. 2015;19(1):45-50

6. Jefee-Bahloul H, Moustafa MK, Shebl FM, Barkil-Oteo A. Pilot assessment and survey of Syrian refugees' psychological stress and openness to referral for telepsychiatry (PASSPORT study). Telemed E-Health. 2014;20(10):977-9.

7. Marlowe JM. Beyond the discourse of trauma: shifting the focus on Sudanese refugees. J Refug Stud. 2010;23:183-8.

8. Miller KE, Rasmussen A. War exposure, daily stressors, and mental health in conflict and post-conflict settings: bridging the divide between traumafocused and psychosocial frameworks. Soc Sci Med. 2010;70(1):7-16.

9. Tekeli-Yesil S, Isik E, Unal Y, Aljomaa Almossa F, Konsuk Unlu H, Aker AT. Determinants of mental disorders in Syrian refugees in Turkey versus internally displaced persons in Syria. Am J Public Health. 2018;108(7):938-45.

10. Ben Farhat J, Blanchet K, Juul Bjertrup P, Veizis A, Perrin C, Coulborn $\mathrm{RM}$, et al. Syrian refugees in Greece: experience with violence, mental health status, and access to information during the journey and while in Greece. BMC Med. 2018;16(1):40.

11. Chen W, Hall BJ, Ling L, Renzaho AM. Pre-migration and post-migration factors associated with mental health in humanitarian migrants in Australia and the moderation effect of post-migration stressors: findings from the first wave data of the BNLA cohort study. Lancet Psychiatry. 2017;4(3):218-9.

12. Laban $\mathrm{CJ}$, Komproe $\mathbb{H}$, Gernaat HB, de Jong JT. The impact of a long asylum procedure on quality of life, disability and physical health in Iraqi asylum seekers in the Netherlands. Soc Psychiatry Psychiatr Epidemiol. 2008;43(7):507.

13. Steel Z, Silove D, Brooks R, Momartin S, Alzuhairi B, Susljik INA. Impact of immigration detention and temporary protection on the mental health of refugees. Br J Psychiatry. 2006;188:58-64.

14. Jordans MJ, Semrau M, Thornicroft G, van Ommeren M. Role of current perceived needs in explaining the association between past trauma exposure and distress in humanitarian settings in Jordan and Nepal. Br J Psychiatry. 2012;201(4):276-81.

15. Hassan G, Ventevogel P, Jefee-Bahloul H, Barkil-Oteo A, Kirmayer LJ. Mental health and psychosocial wellbeing of Syrians affected by armed conflict. Epidemiol Psychiatr Sci. 2016;25(2):129-41. 
16. Ventevogel $P$, van $O M$, Schilperoord M, Saxena S. Improving mental health care in humanitarian emergencies. Bull World Health Organ. 2015;93(10):666

17. Yoon E, Chang C-T, Kim S, Clawson A, Cleary SE, Hansen M, et al. A meta-analysis of acculturation/enculturation and mental health. J Couns Psychol. 2013;60(1):15-30.

18. Keller AS, Rosenfeld B, Trinh-Shevrin C, Meserve C, Sachs E, Leviss JA, et al. Mental health of detained asylum seekers. Lancet. 2003;362(9397):1721-3.

19. Kilzieh N, Rastam S, Ward KD, Maziak W. Gender, depression and physical impairment: an epidemiologic perspective from Aleppo, Syria. Soc Psychiatry Psychiatr Epidemiol. 2010;45(6):595-602.

20. Gammouh OS, Al-Smadi AM, Tawalbeh LI, Khoury LS. Peer reviewed: Chronic diseases, lack of medications, and depression among Syrian refugees in Jordan, 2013-2014. Prev Chronic Dis. 2015;12:140424.

21. Council of the European Union. EU-Turkey statement. 2016.

22. Kroenke K, Strine TW, Spitzer RL, Williams JB, Berry JT, Mokdad AH. The PHQ8 as a measure of current depression in the general population. J Affect Disord. 2009:114(1-3):163-73.

23. Feyera F, Mihretie G, Bedaso A, Gedle D, Kumera G. Prevalence of depression and associated factors among Somali refugee at melkadida camp, Southeast Ethiopia: a cross-sectional study. BMC Psychiatry. 2015;15:171.

24. Beutel ME, Jünger $C$, Klein EM, Wild $P$, Lackner KJ, Blettner $M$, et al. Depression, anxiety and suicidal ideation among 1 st and 2 nd generation migrants-results from the Gutenberg health study. BMC Psychiatry. 2016;16(1):288.

25. AlHadi AN, AlAteeq DA, Al-Sharif E, Bawazeer HM, Alanazi H, AlShomrani AT, et al. An arabic translation, reliability, and validation of patient health questionnaire in a Saudi sample. Ann General Psychiatry. 2017;16:32

26. Sawaya H, Atoui M, Hamadeh A, Zeinoun P, Nahas Z. Adaptation and initial validation of the patient health questionnaire-9 (PHQ-9) and the generalized anxiety disorder-7 questionnaire (GAD-7) in an Arabic speaking Lebanese psychiatric outpatient sample. Psychiatry Res. 2016;239:245-52.

27. Kroenke K, Spitzer RL. The PHQ-9: a new depression diagnostic and severity measure. Psychiatr Ann. 2002;32:509-15.

28. American Psychiatric Association. Diagnostic and statistical manual of mental disorders. 5th ed. Arlington, VA: American Psychiatric Publishing; 2013.

29. Blom MB, Spinhoven P, Hoffman T, Jonker K, Hoencamp E, Haffmans PJ, et al. Severity and duration of depression, not personality factors, predict short term outcome in the treatment of major depression. J Affect Disord. 2007;104(1-3):119-26.

30. Burstein $\mathrm{H}$. Finite population correction for binomial confidence limits. J Am Stat Assoc. 1975;70:67-9.

31. Kessler RC, Sampson NA, Berglund P, Gruber MJ, Al-Hamzawi A, Andrade L, et al. Anxious and non-anxious major depressive disorder in the World Health Organization world mental health surveys. Epidemiol Psychiatr Sci. 2015;24(3):210-26.

32. Mirowsky J, Ross CE. Age and depression. J Health Soc Behav. 1992;33(3):187-205.

33. Bjelland I, Krokstad S, Mykletun A, Dahl AA, Tell GS, Tambs K. Does a higher educational level protect against anxiety and depression? The HUNT study. Soc Sci Med. 2008;66(6):1334-45.

34. LaPierre TA. Marital status and depressive symptoms over time: age and gender variations. Fam Relat. 2009;58:404-16.

35. Husain N, Creed F, Tomenson B. Depression and social stress in Pakistan. Psychol Med. 2000;30:395-402.

36. Steel Z, Chey T, Silove D, Marnane C, Bryant RA, Van Ommeren M. Association of torture and other potentially traumatic events with mental health outcomes among populations exposed to mass conflict and displacement: a systematic review and meta-analysis. JAMA. 2009;302(5):537-49.

37. StataCorp. Stata statistical software: Release 14.2. TX: College Station; 2016.

38. Ferrari AJ, Charlson FJ, Norman RE, Patten SB, Freedman G, Murray CJ, et al. Burden of depressive disorders by country, sex, age, and year: findings from the global burden of disease study 2010. PLoS Med. 2013;10(11):e1001547.

39. Heeren M, Wittmann L, Ehlert U, Schnyder U, Maier T, Müller J. Psychopathology and resident status-comparing asylum seekers, refugees, illegal migrants, labor migrants, and residents. Compr Psychiatry. 2014:55(4):818-25.

40. Lindert J, von Ehrenstein OS, Priebe S, Mielck A, Brähler E. Depression and anxiety in labor migrants and refugees-a systematic review and metaanalysis. Soc Sci Med. 2009;69(2):246-57.

41. World Health Organization. The Global Burden of Disease: Update [Internet]. Geneva, Switzerland: World Health Organization; 2004.
Available from: http://www.who.int/healthinfo/global_burden_disease/ GBD report 2004update full.pdf.

42. Weissman MM, Klerman GL. Sex differences and the epidemiology of depression. Arch Gen Psychiatry. 1977:34:98-111.

43. England MJ, Sim LJ. Depression in parents, parenting, and children: opportunities to improve identification, treatment, and prevention. Washington, DC: National Academies Press; 2009. Available from: http:// psycnet.apa.org/psycinfo/2009-10867-000.

44. Bryant RA, Edwards B, Creamer M, O'Donnell M, Forbes D, Felmingham $\mathrm{KL}$, et al. The effect of post-traumatic stress disorder on refugees' parenting and their children's mental health: a cohort study. Lancet Public Health. 2018;3(5):e249-58.

45. Garber J, Ciesla JA, McCauley E, Diamond G, Schloredt KA. Remission of depression in parents: links to healthy functioning in their children. Child Dev. 2011:82(1):226-43.

46. Bärnighausen T, Bor J, Wandira-Kazibwe S, Canning D. Correcting HIV prevalence estimates for survey nonparticipation using Heckman-type selection models. Epidemiol Camb Mass. 2011;22(1):27-35.

47. Hogan DR, Salomon JA, Canning D, Hammitt JK, Zaslavsky AM, Bärnighausen T. National HIV prevalence estimates for sub-Saharan Africa: controlling selection bias with Heckman-type selection models. Sex Transm Infect. 2012:88(Suppl 2):i17-23.

48. McGovern ME, Marra G, Radice R, Canning D, Newell M-L, Bärnighausen T. Adjusting HIV prevalence estimates for non-participation: an application to demographic surveillance. J Int AIDS Soc. 2015;18:19954.

49. McGovern ME, Bärnighausen T, Salomon JA, Canning D. Using interviewer random effects to remove selection bias from HIV prevalence estimates. BMC Med Res Methodol. 2015;15:8.

50. World Health Organization and United Nations High Commissioner for Refugees. mhGAP Humanitarian Intervention Guide (mhGAP-HIG): Clinical management of mental, neurological and substance use conditions in humanitarian emergencies. Geneva: WHO; 2015. http://www.who.int/ mental_health/publications/mhgap_hig/en/.

51. Mohr DC, Vella L, Hart S, Heckman T, Simon G. The effect of telephoneadministered psychotherapy on symptoms of depression and attrition: a meta-analysis. Clin Psychol Sci Pract. 2008;15(3):243-53.

52. Musyimi CW, Mutiso VN, Haji ZR, Nandoya ES, Ndetei DM. Mobile based mhGAP-IG depression screening in Kenya. Community Ment Health J. 2018:54(1):84-91.

53. Sijbrandij M, Acarturk C, Bird M, Bryant RA, Burchert S, Carswell K, et al. Strengthening mental health care systems for Syrian refugees in Europe and the Middle East: integrating scalable psychological interventions in eight countries. Eur J Psychotraumatology. 2017;8(sup2):1388102.

Ready to submit your research? Choose BMC and benefit from:

- fast, convenient online submission

- thorough peer review by experienced researchers in your field

- rapid publication on acceptance

- support for research data, including large and complex data types

- gold Open Access which fosters wider collaboration and increased citations

- maximum visibility for your research: over $100 \mathrm{M}$ website views per year

At BMC, research is always in progress.

Learn more biomedcentral.com/submission 